\title{
Epigenetic Modifications: Are we Closer to Clinical Applicability?
}

\section{Frederique Ponchel ${ }^{*}$ and Agata N Burska}

The Leeds Trust Teaching Hospital, The University of Leeds \& NIHR Leeds Musculoskeletal Biomedical Research Unit, Leeds, UK

* Corresponding author: Frederique Ponchel, The Leeds Trust Teaching Hospital, The University of Leeds \& NIHR Leeds Musculoskeletal Biomedical Research Unit, Leeds, UK, Tel: (0)1132065642; E-mail: F.Ponchel@leeds.ac.uk

Received date: May 05, 2016; Accepted date: June 03, 2016; Published date: June 10, 2016

Copyright: $\odot 2016$ Ponchel F, et al. This is an open-access article distributed under the terms of the Creative Commons Attribution License, which permits unrestricted use, distribution, and reproduction in any medium, provided the original author and source are credited.

\begin{abstract}
Epigenetics encompass all inheritable, although potentially reversible changes in the genome, that do not alter the DNA code, but result from both developmentally (ensuring tissue specificity) and environmentally (resulting for exposure to many factors) driven modification of the spatial conformation of the DNA through chemical modification of the nucleotide chain itself or of the chromatin associated proteins. Epigenetic controls gene expression at a higher level than transcription, imputing on the genome an environmental signature that is heritable through cell division and reflects a life-long experience. These types of modification (particularly DNA methylation patterns) explain phenotypic differences between identical twins. As opposed to genetic mutation, these modifications are reversible and are controlled by groups of enzymes (the epigenetic machinery, DNA methyltransferases (DNMT), histone deacetylases (HDACs) and histone acetyl transferases (HATs) and many more), hence, epigenetic marks include DNA methylation, histone modification and nucleosome positioning resulting in higher structural organisation of the chromatin regulating gene expression at the level of DNA accessibility for the transcriptional machinery to bind and initiate transcription.
\end{abstract}

\section{Introduction:}

Over the past few years, epigenetics has become an important field of research. Although epigenetic modifications to the genome do not involve a change in the nucleotide sequence, such alterations are important in all the processes that differentiate cells into several types contributing towards developing different tissues and patterns of epigenetic modification are transmitted to daughter cells with high fidelity and even across generations [1-3].

Several diseases have been related to alteration in such patterns and much research is now investigating how a variety of epigenetic mechanisms can be perturbed. The field has advanced predominantly in cancer, where perturbations include silencing of tumor suppressor genes and activation of oncogenes through change of $\mathrm{CpG}$ island methylation patterns, histone modifications, and dysregulation of DNA binding proteins. Such alteration in the epigenetic patterns are now considered as epigenetic mutations (epimutation) and are as important in tumorigenesis as genetic mutations, to the point that today cancer is thought to be the results of both genetic and epigenetic modifications [4-6]. Autoimmune diseases share a common origin in immunogenetic mechanisms. Epigenetic mechanisms are therefore also thought to be of importance as well in the pathogenesis of such complex diseases. DNA methylation has recently become the most widely studied mechanism in autoimmune diseases, with findings similar to those observed in cancer, notably in systemic lupus erythematosus (SLE) and rheumatoid arthritis (RA) [7].

\section{DNA methylation}

DNA methylations regulate an essential status of the chromatin (euchromatin or heterochromatin) by modulating nucleosomes spatial distribution and controlling DNA packaging through the binding of protein specifically recognizing methylated DNA and leading to chromatin compaction [8]. In humans, transcriptionally active genes globally present non-methylated $\mathrm{CpG}$ island (s) preceding their promoter whereas the rest of $\mathrm{CpG}$ dinucleotides (50-70\%) throughout the genome primarily in the heterochromatin regions are methylated towards silencing this part of the genome and contributing to chromosomal stability $[9,10]$. In contract, in cancer or other diseases, the "healthy" CpG methylation profile of a cell is often inverted, almost mirrored [11] and tumor cells possess a globally hypomethylated genome, while at the same time focal hypermethylation is increased in specific places of the genome $[4,12]$. Islands preceding "anti-cancer" genes promoters are "closed" through hypermethylation, while oncogene promoters are "opened" by de-methylation. A number of genes have notably been implicated in cancer both genetically and epigenetically (the cyclin-dependent kinase inhibitor p16, the DNA repair genes MutL-homolog-1, O-6-methylguanine-DNA methyltransferase (MGMT) or breast cancer type 1 susceptibility protein, the cell cycle regulator Adenomatous polyposis coli $[11,13])$. On one hand, hypomethylation (which is estimated to be $20-50 \%$ less than normal in cancer) by disrupting the normal state of the chromatin, was shown to lead to chromosome instability by rendering accessible regions often containing retro-transposons (such as LINE-1 repeats), satellite DNA, and moderately repeated DNA sequences, whereas genes containing CpG clusters become hypermethylated, rendering them transcriptionally silent $[4,12,14,15]$ This often includes promotor regions for genes themselves implicated in methylation (such as DNA methyltransferases) as is also observed in an inflammatory disease RA [16]. On the other hand, hypermethylation resulting in gene silencing can become so extensive that it has been tagged as addictive [17].

In SLE there is hypomethylation of promoter for genes overexpressed in the disease (Integrin, alpha L (ITGAL), CD40-Ligand, Perforin-1, CD70, Interferon gamma receptor 2, Matrix metalloproteinase-14, Lipocalin-2 [18-22] causing T-cell hyperactivity to perpetuate inflammatory responses [23-25], B cells to overexpress CD5 promoting autoimmunity [26]. In RA, synovial fibroblasts are 
though to play a role in the initiation and perpetuation of the disease [27]. These cells were found to be globally hypomethylated resulting in the overexpression of inflammatory cytokines [28-30], similarly to LINE-1 elements [31,32]. On the other hand, hypomethylation of CpG islands in the IL-6 promoter gene resulting in overexpression contributes to B-cell responses [33,34] Synovial cells resistance to apoptosis was also associated with hypermethylation of death receptor 3 (DR-3) gene [32,35-37]. In type 1 diabetes mellitus (T1DM) there is global hypermethylation related to altered metabolism of homocysteine in T-cells modulating their maturation and cytokine gene expression $[38,39]$. Multiple sclerosis (MS) is a unique case as the autoantigen (myelin basic protein) is known. The promotor of the peptidyl arginine deiminase type II (PAD2), the enzyme modifying myelin, is hypomethylated [40,41]. Systemic Sclerosis (SSc) is characterized by excessive collagen deposits in skin and other tissues. Hypermethylation of the Fli1 promoter, the transcription factor inhibiting collagen production is associated with this pathology $[42,43]$.

\section{Histone modification}

DNA packaging includes wrapping around nucleosomes which can be more or less spatially tightened/loosen by post translational modification of the chromatin (DNA and histones proteins), allowing transcription to take place with more or less efficacy. Histones notably serve as building blocks to package DNA into higher or lower order of chromatin fibers and as such coordinate the changes between heterochromatin (tightly packed DNA "closed" to transcription) and euchromatin (exposed DNA, "open" for the binding of transcription factors [44]. Again, histone modifications (methylation, acetylation, phosphorylation, ubiquitination, sumoylation or biotinylation) follow a very specific pattern in healthy situation which can be altered by diseases. The loss of a particular modification (histone H4 lysine 16 acetylation (H4K16ac)) affects telomeres length during normal ageing and is targeted in cancer towards immortalising cells [11,45]. Both qualitative and quantitative changes in histone modifications are observed in cancer (much literature available), including many position and type of modification: $\mathrm{H} 3 \mathrm{~K} 4 \mathrm{me} 3, \mathrm{H} 3 \mathrm{~K} 4 \mathrm{me} 2, \mathrm{H} 3 \mathrm{ac}$ are heavily enriched genome wide while $\mathrm{H} 3 \mathrm{~K} 4 \mathrm{mel}$ and $\mathrm{H} 4 \mathrm{ac}$ shown reduced enrichment, $\mathrm{H} 3 \mathrm{~K} 4 \mathrm{me} 1$ and $\mathrm{H} 3 \mathrm{~K} 36 \mathrm{me} 3$ display aberrant distributions whereas $\mathrm{H} 3 \mathrm{~K} 9 \mathrm{me} 1, \mathrm{H} 3 \mathrm{~K} 20 \mathrm{mel}$ and H3K27me1 show elevated levels of modification at specific gene loci and high levels of $\mathrm{H} 3 \mathrm{~K} 27 \mathrm{me} 2,3$, H3K79me3 H3K9me2, 3 were linked to gene repression or silencing). The expression of specific genes is also modulated at individual levels through such mechanisms in advanced cancers and metastasis either activating oncogenes (Myc) or silencing tumor suppressors (p53) [46-49]. Again, the machinery involved in making/ erasing such modifications is often itself the target of dysregulation by these mechanisms (histone acetyltransferases, histone deacetylase) $[11,50,51]$.

Nucleosomes are the primary inciting antigen in SLE. Histones are rendered immunogenic by the introduction of modifications (H3K4me3, H4K8, H3K27me3, H2BK12ac) during apoptosis, leading to the development of auto-antibodies [38,50-55]. In RA, the activity of HAT and HDAC is altered through histones acetylation resulting in matrix metalloproteinases and their regulators mediating cartilage destruction [56-58]. In mice models, histones hyperacetylation was associated with the induction of cell cycle arrest via p16 and p21 cyclin-dependent kinase inhibitors and a decrease in tumour necrosis factor- alpha synthesis the downregulation of hypoxia inducible factor and vascular endothelial growth factor ameliorating arthritis [58-60].
In T1DM, a few genes associated with autoimmunity and inflammation (cytotoxic T-lymphocyte-associated protein 4 (CLTA4), transforming growth factor-beta, nuclear factor kappa-light-chainenhancer of activated B cells (NF- $\mathrm{B}$ ), mitogen-activated protein kinase $\mathrm{p} 38$, toll-like receptors, and Ineterleukin-6) were shown to exhibit dysregulated histone modification (H3K9me2) in lymphocytes [61-63]. Cardiovascular complications were also associated with Histone modifications (H3K4 and H3K9) [62-64]. In MS, increase in histone acetylation in the white matter was observed as well as hyperacetylation of histones in the promoter region of inhibitory genes involved in oligodendrocyte differentiation (Transcription factor 7-like 2, DNA-binding protein inhibitor ID-2, and sex determining region Ybox 2 (SOX2)) [65].

\section{Nucleosome positioning}

Nucleosome positioning patterns play an essential role in regulating gene expression. Nucleosomes too close to a transcription start sites (as small as $30 \mathrm{BP}$ shit) may prevent transcription factors' to access the DNA hence, a nucleosome-free region need to allow the assembly of the transcription machinery [66]. Nucleosome positioning is itself regulated by as well as can influence DNA methylation [67]. This mechanism is important but has been studied in less detail so far. High-resolution genome-wide maps of nucleosome positions have so far provided much information about the organization of gene promoter and how this can facilitate or inhibit transcription [68]. Nucleosome position was notably shown to alter the pattern of expression of different splicing forms of genes responding to progesterone stimulation in breast cancer cells [69].

In RA, the binding of transcription factor NF- $\mathrm{BB}$ to target gene appear altered by nucleosome positioning [70]. Difference in nucleosome distribution was also associated with genetic susceptibility to several autoimmune diseases (asthma, T1DM, Crohn's disease, cirrhosis) [70]. A polymorphism in region 17q12-q21 was associated with changes in expression of 2 genes (gasdermin B and ORM1-like 3 (ORMDL3)) resulting in allele-specific change in nucleosome distribution [70].

\section{Technological advances}

Analysing methylation at the genome level (epigenome-wide EWAS) is now relatively accessible. DNA methylation arrays technology is robust although it is dependent on the identification of CpG islands across the genome. The Human Methylation-450K CpG BeadChip kit has now been widely used, offering comprehensive coverage (96\% of the known islands/promoters) and an affordable solution; however targeting only known promoters. The second generation EWAS kit $(850 \mathrm{~K} \mathrm{CpG})$ will offer coverage of promoters and enhancer, allowing more insight into to fine details of gene expression regulation. Microarrays may be replaced in the future by next generation sequencing technologies [71]; however, microarray are still very useful to pilot project or for large-scale experiments. The methylated DNA immunoprecipitation (MeDIP) technology [72] allows to immunoprecipitate single-stranded DNA fragments containing methylated DNA on a large scale for a chromosome or the whole genome. Combined with next-generation sequencing, MeDIPSeq can stream down the analysis of the methylome by imputing methylation enriched DNA. Despite databases such as the GenomeStudio Browser displaying valuable information about chromosomal coordinates, island, percent GC, location in the CpG island allowing the analysis of the differential methylation between 
samples of interest; it still remains quite difficult to analysed genome wide epigenetic data $[73,74]$. Tools are available; however they are much less advanced than in the genetics or gene expression filed [75-77]. One the main issue is that tissues are formed of different types of cells and each will have a different epigenetic signature, and unlike genetic information (static), epigenetics is changing with time (dynamic). New bioinformatics tools are also trying to combine GWAS data with EWAS data, to integrate genetic and environmental exposure information into disease context, however no publicly available databases for EWAS data have been set-up yet. The metyhylation profile of repeated element (ALU, LINE SINE) mobile elements has not been fully completed and the impact of the repeat sequences has not been incorporated into the available tools to analyze EWAS.

Chromatin Immunoprecipitation (ChIP) represents the gold standard for analyzing protein based epigenetic marks [78]. It offers very specific information on proteins (histone or transcription factors $(\mathrm{TF})$ ) associated with a particular genomic region, such as a promoter. Due to the immunoprecipitation step, it looks at one particular modification or TF (targeted by the antibody) but can be coupled to PCR for one specific gene (as for biomarker development) or next generation sequencing to assess the overall role of that modification/TF. Histone profiling also requires high-quality monoclonal antibodies of which few are commercially available. A major effort by the NIH Epigenome Roadmap has launched a programme towards generating antibodies against all major histone modifications to be made readily available to investigators.

\section{Epimutations: cause or consequences?}

Distinct defect associated with epigenetic mechanisms are now widely reported in cancer (and start to be described in other diseases). Furthermore, many factors with long lasting association with diseases (mostly cancer); do not have mutagenic ability despite being classified as carcinogens (arsenite, chlorobenzene, nickel). These (as well as teratogens) were shown to exert their effect through epigenetic mechanisms $[79,80]$ providing further links between such mechanism and the occurrence of diseases.

These often target genes implicated in DNA repair as much as the epigenetic machinery itself. The question then arises whether they were an early event leading to carcinogenesis or a later consequence of the overall genetic instability. Point or larger size mutation are unlikely to be causing major cell function disruption if not associated with a mechanism allowing the development of the phenotype (cancer, other diseases) associated with the expression of these defective genes. DNA repair mechanisms are also challenged by the presence of methylated cytosine, creating a "lesion" that cannot easily be discriminated and resulting in an increase in G:T mismatch mutation. A conceptual argument was therefore made for an early involvement as a mean to lower the "proof reading" capability of cells, allowing DNA damage to persist unchecked. Accumulation of DNA damage thereafter can cause further increase in epimutation and vice versa [81]. Similar epimutations were also found in the area surrounding tumors suggesting a wider local perturbation possibly being the cause of an initial epigenetic event. If much descriptive work has demonstrated the presence and effect of such alterations, the precise nature of an original epigenetic switch is still elusive, in cancer as well as on other diseases although in the case of autoimmune disorders, inflammation appears a likely candidate. Nonetheless, the development of aberrant epigenomics was associated with all phases of cancer from initiation, promotion, invasion, metastasis, and chemotherapy resistance $[5,8,82-89]$ both at the genome wide and gene specific levels.

\section{Epigenetic biomarkers}

Since epigenetic marks are non-permanent, it was hypothesized that epigenomic profiles or specific epigenetic changes could be used to diagnose diseases, establish stages or predict response to treatment. Profiling methylation and acetylation with high accuracy is now a relatively "easy" approach thanks to recent advances in epigenomic analysis technologies. Epigenetic marks being defined as hallmarks of certain diseases, specific methylated $\mathrm{CpG}$ sites were investigated as biomarkers for diagnosis, staging, prognosis, and prediction of response to therapy [90]. For example hypermethylation silencing of certain loci (cadherin-13 (CDH13), myogenic regulator MYOD1, MGMT, cyclin-dependent kinase inhibitor p16-INK4b, glutathione Stransferase $\mathrm{P}$, Ras association domain-containing protein 1, retinoic acid receptor RARB2, APC,) was specific to several cancer types $[8,91,92]$ providing diagnostic value. Similarly, the hypermethylation of p16 and CDH13 has been associated with higher death risk and relapse [93]. Repetitive or mobile DNA elements (SINEs and LINEs) are hypomethylated in cancers [94], although to date the clinical utility of this remains unclear. Certain histone acetylation were also associated with poor prognosis $[95,96]$, while other had diagnostic value [97]. Several chemotherapy drug are attacking the genome although for cancer cell to dye (by apoptosis), methylation and silencing of DNA repair mechanism must not have taken place yet hence, investigating these provides a means to predict response to treatment [98-101]. These observations still need to be reproduced and validated in large patient cohorts but implementation may not be far from clinical practice $[96,102,103]$.

Epigenetic biomarker assay have therefore been developed by several companies. A test for the loci specific analysis of DNAmethylation levels was developed (Cygenia) for the complement component 1 subcomponent $\mathrm{R}(\mathrm{C} 1 \mathrm{R})$ gene which is indicative of overall survival in acute myeloid leukemia (AML) [104]. Metastatic colorectal cancer patients with a lack of response to certain drug combination was associated with hypermethylation of the decoy receptor 1 (DCR1) gene [105]. Based on this a predictive biomarker test was introduced measuring levels of hypermethylation of the DCR1 gene. Further test will soon offer the possibility to measure the global methylation level at the DNA-methyltransferase 3A (DNMT3A) locus (epimutation) as a prognostic factor for AML [106]where both mutation and epimutations were associated with an elevated risk score and poor prognosis (patent pending)). Another will quantify the abnormal shortening of telomeres epigenetically controlled at the PR domain containing-8 (PRDM8) gene in association with ageing and aplastic anemia or dyskeratosis congenital [105] Episona. The field is less advanced in other diseases although, the role Th17 cells in autoimmune diseases has been established and quantifying these cells in the blood of patients with RA using a commercial assay detecting an epigenetic mark on the IL-17 gene was recently proposed as a diagnostic marker for RA [107].

\section{Therapy targeting epigenetic mechanisms}

Treatment (and prevention) strategies nowadays must take in consideration the role of epigenetic changes in the pathogenesis as well as progression of diseases. On the other hand, epigenetic changes are not permanently imprinted but result from enzymatic modifications of the DNA or histones. As such a therapeutic rational was developed to 
target such reversible changes. The epigenetic enzymes are the target of drug design for activity inhibitors mostly of the DNMT or HDAC. 5azacytidine and 5-aza-2'-deoxycitidine are both nucleoside analogs and DNMT inhibitors. They showed much promises in in vitro model but due to the fact that these drugs affect the epigenome widely, that they cannot penetrate deeply inside solid cancer mass and have severe toxic side effects, they are now being replace by other means of targeting DNMT, which are more specific and less toxic (anti-sense and small molecule) $[108,109]$. In clinical trials, HDAC inhibitors (butyrate, trichostatin A (TSA), depsipeptide, oxamflatin, MS-275) showed better tolerability and more activity with objective tumor regression $[110,111])$. They appear to induce the expression of regulators of the cell-cycle, causing cell-cycle arrest [110,112]. A combination of DNMT and HDAC inhibitors has been proposed as a novel approach for therapeutic intervention as it showed a synergistic reactivation of tumor suppressor genes and an enhanced antineoplastic effect against tumor cells [95]. Procainamide and hydralazine are two drugs used in SLE that are ultimately result in the inhibition of DNA methylation through different pathways [113-119].

Epigenetic is often associated with the quote "We are what we eat and breath" as a recognition of the impact of our diet and environment on our health [120]. Relationships between these factors and cancer and other diseases have been clearly established [94,121,122]. Glucose and insulin levels are factor regulating methylation by modulating the activity of DNMT [123-125]. Several component of our diet were shown to have inhibitory activity on the epigenetic machinery such as dietary chemopreventive agents (butyrate, diallyl disulfide, sulforaphane) on HDAC [126], a plant molecule (resveratrol) on Sirtuin-1 [127] and green tea (polyphenols and phenethyl isothiocyanate) on both DNMT and HDAC $[128,129]$. On the other hands, transposons and other mobile genetic elements can be activated by different types of environmental stress including dietary stress [130-131].

\section{Conclusion}

The underlying goals for most epigenetic research is both to understand the role of epigenetic mechanisms in health and diseases and ultimately, to developed biomarkers or therapeutic interventions. Epigenetic has certainly delivered many new insights into the understanding of the initiation, progression and response to therapy for diseases such as cancer and autoimmune conditions. Recent advances in technologies are with no doubts an important factor in this and will certainly continue to contribute novel development in the biomarker field. The therapeutic potential of novel HDAC and DNMT inhibitors is promising and following from the genetic and then the transcriptomic and proteomic eras, epigenetic may now offer the missing link allowing the integration of our life experience into our health.

\section{References}

1. Jirtle RL, Skinner MK (2007) Environmental epigenomics and disease susceptibility. Nat Rev Genet 8: 253-262.

2. Skinner MK (2011) Role of epigenetics in developmental biology and transgenerational inheritance. Birth Defects Res C Embryo Today 93: 51-55.

3. Guerrero-Bosagna C, Skinner MK (2012) Environmentally induced epigenetic transgenerational inheritance of phenotype and disease. Molecular and cellular endocrinology 354: 3-8.
4. Baba S, Yamada Y, Hatano Y, Miyazaki Y, Mori H, et al. (2009) Global DNA hypomethylation suppresses squamous carcinogenesis in the tongue and esophagus. Cancer Sci 100: 1186-1191.

5. Ellis, Atadja PW, Johnstone RW (2009) Epigenetics in cancer: targeting chromatin modifications. Mol Cancer Ther 8: 1409-1420.

6. Zheng SC, Widschwendter M, Teschendorff AE (2016) Epigenetic drift, epigenetic clocks and cancer risk. Epigenomics 8: 705-719.

7. Cribbs A, Feldmann M, Oppermann U (2015) Towards an understanding of the role of DNA methylation in rheumatoid arthritis: therapeutic and diagnostic implications. Ther Adv Musculoskelet Dis 7: 206-219.

8. Dehan P, Kustermans G, Guenin S, Horion J, Boniver J, et al. (2009) DNA methylation and cancer diagnosis: new methods and applications. Expert Rev Mol Diagn 9: 651-657.

9. Grewal SI, Moazed D (2003) Heterochromatin and epigenetic control of gene expression. Science 301: 798-802.

10. Haberland M, Montgomery RL, Olson EN (2009) The many roles of histone deacetylases in development and physiology: implications for disease and therapy. Nat Rev Genet 10: 32-42.

11. Esteller M (2007) Cancer epigenomics: DNA methylomes and histonemodification maps. Nat Rev Genet 8: 286-298.

12. Reik W, Dean W, Walter J (2001) Epigenetic reprogramming in mammalian development. Science 293: 1089-1093.

13. Jones PA, Baylin SB (2002) The fundamental role of epigenetic events in cancer. Nat Rev Genet 3: 415-428.

14. Esteller M (2005) Aberrant DNA methylation as a cancer-inducing mechanism. Annu Rev Pharmacol Toxicol 45: 629-656.

15. Herman JG, Baylin SB (2003) Gene silencing in cancer in association with promoter hypermethylation. N Engl J Med 349: 2042-2054.

16. Ponchel F, Chambers P, Droop A, Parmar R, Halstead-Rastrick J, et al. (2015) A1.22 NaÏve and memory CD4+T-cell DNA methylation profile in RA. Annals of the Rheumatic Diseases 74: A9-A10.

17. De Carvalho DD, Sharma S, You JS, Su SF, Taberlay PC, et al. (2012) DNA methylation screening identifies driver epigenetic events of cancer cell survival. Cancer Cell 21: 655-667.

18. Lu Q, Kaplan M, Ray D, Ray D, Zacharek S, et al. (2002) Demethylation of ITGAL (CD11a) regulatory sequences in systemic lupus erythematosus. Arthritis Rheum 46: 1282-1291.

19. Lu Q, Wu A, Tesmer L, Ray D, Yousif N, et al. (2007) Demethylation of CD40LG on the inactive $\mathrm{X}$ in $\mathrm{T}$ cells from women with lupus. J Immunol 179: 6352-6358.

20. Kaplan MJ, Lu Q, Wu A, Attwood J, Richardson B (2004) Demethylation of promoter regulatory elements contributes to perforin overexpression in CD4+ lupus T cells. J Immunol 172: 3652-3661.

21. Oelke K, Lu Q, Richardson D, Wu A, Deng C, et al. (2004) Overexpression of CD70 and overstimulation of IgG synthesis by lupus T cells and $\mathrm{T}$ cells treated with DNA methylation inhibitors. Arthritis Rheum 50: 1850-1860.

22. Javierre BM, Fernandez AF, Richter J, Al-Shahrour F, Martin-Subero JI, et al. (2010) Changes in the pattern of DNA methylation associate with twin discordance in systemic lupus erythematosus. Genome Res 20: 170-179.

23. Lei W, Luo Y, Lei W, Luo Y, Yan K, et al. (2009) Abnormal DNA methylation in $\mathrm{CD} 4+\mathrm{T}$ cells from patients with systemic lupus erythematosus, systemic sclerosis, and dermatomyositis. Scand J Rheumatol 38: 369-374.

24. Lu Q, Wu A, Ray D, Deng C, Attwood J, et al. (2003) DNA methylation and chromatin structure regulate $\mathrm{T}$ cell perforin gene expression. J Immunol 170: 5124-5132.

25. Lu Q, Ray D, Gutsch D, Richardson B (2002) Effect of DNA methylation and chromatin structure on ITGAL expression. Blood 99: 4503-4508.

26. Garaud S, Le Dantec C, Jousse-Joulin S, Hanrotel-Saliou C, Saraux A, et al. (2009) IL-6 modulates CD5 expression in B cells from patients with lupus by regulating DNA methylation. J Immunol 182: 5623-5632.

27. Karouzakis E, Gay RE, Michel BA, Gay S, Neidhart M (2009) DNA hypomethylation in rheumatoid arthritis synovial fibroblasts. Arthritis Rheum 60: 3613-3622. 
28. Maciejewska-Rodrigues H, Karouzakis E, Strietholt S, Hemmatazad H, Neidhart M, et al. (2010) Epigenetics and rheumatoid arthritis: the role of SENP1 in the regulation of MMP-1 expression. J Autoimmun 35: 15-22.

29. Fu LH, Ma CL, Cong B, Li SJ, Chen HY, et al. (2011) Hypomethylation of proximal CpG motif of interleukin-10 promoter regulates its expression in human rheumatoid arthritis. Acta Pharmacol Sin 32: 1373-1380.

30. Kim YI, Logan JW, Mason JB, Roubenoff R (1996) DNA hypomethylation in inflammatory arthritis: reversal with methotrexate. J Lab Clin Med 128: 165-172.

31. Kuchen S, Seemayer CA, Rethage J, von Knoch R, Kuenzler P, et al. (2004) The $\mathrm{L} 1$ retroelement-related $\mathrm{p} 40$ protein induces p38delta MAP kinase. Autoimmunity 37: 57-65.

32. Neidhart M, Rethage J, Kuchen S, Künzler P, Crowl RM, et al. (2000) Retrotransposable L1 elements expressed in rheumatoid arthritis synovial tissue: association with genomic DNA hypomethylation and influence on gene expression. Arthritis Rheum 43: 2634-2647.

33. Nile CJ, Read RC, Akil M, Duff GW, Wilson AG (2008) Methylation status of a single CpG site in the IL6 promoter is related to IL6 messenger RNA levels and rheumatoid arthritis. Arthritis Rheum 58: 2686-2693.

34. Ishida K, Kobayashi T, Ito S, Komatsu Y, Yokoyama T, et al. (2012) Interleukin-6 gene promoter methylation in rheumatoid arthritis and chronic periodontitis. J Periodontol 83: 917-925.

35. De la Rica L, Urquiza JM, Gómez-Cabrero D, Islam AB, López-Bigas N, et al. (2013) Identification of novel markers in rheumatoid arthritis through integrated analysis of DNA methylation and microRNA expression. Journal of Autoimmunity 41: 6-16.

36. Bull MJ, Williams AS, Mecklenburgh Z, Calder CJ, Twohig JP, et al. (2008) The Death Receptor 3-TNF-like protein 1A pathway drives adverse bone pathology in inflammatory arthritis. The Journal of experimental medicine 205: 2457-2464.

37. Osawa K, Takami N, Shiozaw K, Hashiramoto A, Shiozawa S (2004) Death receptor 3 (DR3) gene duplication in a chromosome region 1 p36. 3: gene duplication is more prevalent in rheumatoid arthritis. Genes and Immunity 5: 439-443.

38. Meda F, Folci M, Baccarelli A, Selmi C (2011) The epigenetics of autoimmunity. Cell Mol Immunol 8: 226-236.

39. Stefan M, Zhang W, Concepcion E, Yi Z, Tomer Y (2014) DNA methylation profiles in type 1 diabetes twins point to strong epigenetic effects on etiology. J Autoimmun 50: 33-37.

40. Calabrese R, Zampieri M, Mechelli R, Annibali V, Guastafierro T, et al. (2012) Methylation-dependent PAD2 upregulation in multiple sclerosis peripheral blood. Multiple Sclerosis Journal 18: 299-304.

41. Musse AA, Boggs JM, Harauz G (2006) Deimination of membranebound myelin basic protein in multiple sclerosis exposes an immunodominant epitope. Proceedings of the National Academy of Sciences of the United States of America 103: 4422-4427.

42. Wang Y, Fan PS, Kahaleh B (2006) Association between enhanced type I collagen expression and epigenetic repression of the FLI1 gene in scleroderma fibroblasts. Arthritis Rheum 54: 2271-2279.

43. Kubo M, Czuwara-Ladykowska J, Moussa O, Markiewicz M, Smith E, et al. (2003) Persistent down-regulation of Fli1, a suppressor of collagen transcription, in fibrotic scleroderma skin. Am J Pathol 163: 571-581.

44. Lund AH, van Lohuizen M (2004) Epigenetics and cancer. Genes Dev 18: 2315-2335.

45. Dang W, Steffen KK, Perry R, Dorsey JA, Johnson FB, et al. (2009) Histone H4 lysine 16 acetylation regulates cellular lifespan. Nature 459: 802-807.

46. Aprelikova O, Chen K, Touny EL, Brignatz-Guittard C, Han J, et al. (2016) The epigenetic modifier JMJD6 is amplified in mammary tumors and cooperates with $\mathrm{c}-\mathrm{Myc}$ to enhance cellular transformation, tumor progression, and metastasis. Clinical Epigenetics 8: 1-16.

47. Fraga MF, Ballestar E, Villar-Garea A, Boix-Chornet M, Espada J, et al. (2005) Loss of acetylation at Lys16 and trimethylation at Lys20 of histone H4 is a common hallmark of human cancer. Nat Genet 37: 391-400
48. Richon VM, Sandhoff TM, Rifkind RA, Marks PA (2000) Histone deacetylase inhibitor selectively induces p21WAF1 expression and geneassociated histone acetylation. Proc Natl Acad Sci 97: 10014-10019.

49. Viré E, Brenner C, Deplus R, Blanchon L, Fraga M, et al. (2006) The Polycomb group protein EZH2 directly controls DNA methylation. Nature 439: 871-874.

50. Rappa F, Greco A, Podrini C, Cappello F, Foti M, et al. (2013) Immunopositivity for Histone MacroH2A1 Isoforms Marks SteatosisAssociated Hepatocellular Carcinoma. PLoS One 8: e54458.

51. Ropero S, Fraga MF, Ballestar E, Hamelin R, Yamamoto H, et al. (2006) A truncating mutation of HDAC2 in human cancers confers resistance to histone deacetylase inhibition. Nat Genet 38: 566-569.

52. Schett G, Smolen J, Zimmermann C, Hiesberger H, Hoefler E, et al. (2002) The autoimmune response to chromatin antigens in systemic lupus erythematosus: autoantibodies against histone $\mathrm{H} 1$ are a highly specific marker for SLE associated with increased disease activity. Lupus 11: 704-715.

53. Bruns A, Bläss S, Hausdorf G, Burmester GR, Hiepe F (2000) Nucleosomes are major $\mathrm{T}$ and $\mathrm{B}$ cell autoantigens in systemic lupus erythematosus. Arthritis Rheum 43: 2307-2315.

54. van Bavel CC, Dieker JW, Kroeze Y, Tamboer WP, Voll R, et al. (2011) Apoptosis-induced histone $\mathrm{H} 3$ methylation is targeted by autoantibodies in systemic lupus erythematosus. Ann Rheum Dis 70: 201-207.

55. Hu N, Qiu X, Luo Y, Yuan J, Li Y, et al. (2008) Abnormal histone modification patterns in lupus CD4+ T cells. J Rheumatol 35: 804-810.

56. Buckland J (2011) Rheumatoid arthritis: HDAC and HDACi: pathogenetic and mechanistic insights. Nat Rev Rheumatol 7: 682.

57. Grabiec AM, Reedquist KA (2010) Histone deacetylases in RA: epigenetics and epiphenomena. Arthritis Res Ther 12: 142.

58. Huber LC, Brock M, Hemmatazad H, Giger OT, Moritz F, et al. (2007) Histone deacetylase/acetylase activity in total synovial tissue derived from rheumatoid arthritis and osteoarthritis patients. Arthritis Rheum 56: 1087-1093.

59. Manabe H, Nasu Y, Komiyama T, Furumatsu T, Kitamura A, et al. (2008) Inhibition of histone deacetylase down-regulates the expression of hypoxia-induced vascular endothelial growth factor by rheumatoid synovial fibroblasts. Inflammation Research 57: 4-10.

60. Nishida K, Komiyama T, Miyazawa SI, Shen ZN, Furumatsu T, et al. (2004) Histone deacetylase inhibitor suppression of autoantibodymediated arthritis in mice via regulation of p16INK4a and p21WAF1/ Cip1 expression. Arthritis Rheum 50: 3365-3376.

61. Miao F, Smith DD, Zhang L, Min A, Feng W, et al. (2008) Lymphocytes from patients with type 1 diabetes display a distinct profile of chromatin histone $\mathrm{H} 3$ lysine 9 dimethylation an epigenetic study in diabetes. Diabetes 57: 3189-3198.

62. Li Y, Reddy MA, Miao F, Shanmugam N, Yee JK, et al. (2008) Role of the histone H3 lysine 4 methyltransferase, SET7/9, in the regulation of NF-? B-dependent inflammatory genes relevance to diabetes and inflammation. Journal of Biological Chemistry 283: 26771-26781.

63. Villeneuve LM, Reddy MA, Lanting LL, Wang M, Meng L, et al. (2008) Epigenetic histone H3 lysine 9 methylation in metabolic memory and inflammatory phenotype of vascular smooth muscle cells in diabetes. Proceedings of the National Academy of Sciences 105: 9047-9052.

64. Cooper ME, El-Osta A (2010) Epigenetics: mechanisms and implications for diabetic complications. Circ Res 107: 1403-1413.

65. Pedre X, Mastronardi F, Bruck W, López-Rodas G, Kuhlmann T, et al. (2011) Changed histone acetylation patterns in normal-appearing white matter and early multiple sclerosis lesions. The Journal of Neuroscience 31: 3435-3445.

66. Schones DE, Cui K, Cuddapah S, Roh TY, Barski A, et al. (2008) Dynamic regulation of nucleosome positioning in the human genome. Cell 132: 887-898.

67. Chodavarapu RK, Feng S, Bernatavichute YV, Chen PY, Stroud H, et al. (2010) Relationship between nucleosome positioning and DNA methylation. Nature 466: 388-392. 
68. Jiang C, Pugh BF (2009) Nucleosome positioning and gene regulation: advances through genomics. Nat Rev Genet 10: 161-172.

69. Iannone C, Pohl A, Papasaikas P, Soronellas D, Vicent GP, et al. (2015) Relationship between nucleosome positioning and progesterone-induced alternative splicing in breast cancer cells. RNA 21: 360-374.

70. Choo QY, Ho PC, Tanaka Y, Lin HS (2010) Histone deacetylase inhibitors MS-275 and SAHA induced growth arrest and suppressed lipopolysaccharide-stimulated NF-kappaB p65 nuclear accumulation in human rheumatoid arthritis synovial fibroblastic E11 cells. Rheumatology (Oxford) 49: 1447-1460.

71. Verlaan DJ, Berlivet $S$, Hunninghake GM, Madore AM, Larivière M, et al (2009) Allele-specific chromatin remodeling in the ZPBP2/GSDMB/ ORMDL3 locus associated with the risk of asthma and autoimmune disease. The American Journal of Human Genetics 85: 377-393.

72. Meaburn E, Schulz R (2012) Next generation sequencing in epigenetics: insights and challenges. Semin Cell Dev Biol 23: 192-199.

73. Weber M, Davies JJ, Wittig D, Oakeley EJ, Haase M, et al. (2005) Chromosome-wide and promoter-specific analyses identify sites of differential DNA methylation in normal and transformed human cells. Nature Genetics 37: 853-862.

74. Laird PW (2010) Principles and challenges of genomewide DNA methylation analysis. Nat Rev Genet 11: 191-203.

75. Wilhelm-Benartzi CS, Koestler DC, Karagas MR, Flanagan JM, Christensen BC, et al. (2013) Review of processing and analysis methods for DNA methylation array data. Br J Cancer 109: 1394-1402.

76. Aryee MJ, Jaffe AE, Corrada-Bravo H, Ladd-Acosta C, Feinberg AP, et al. (2014) Minfi: a flexible and comprehensive Bioconductor package for the analysis of Infinium DNA methylation microarrays. Bioinformatics.

77. Wang D, Yan L, Hu Q, Sucheston LE, Higgins MJ, et al. (2012) IMA: an R package for high-throughput analysis of Illumina's 450K Infinium methylation data. Bioinformatics 28: 729-730.

78. Bock C (2012) Analysing and interpreting DNA methylation data. Nat Rev Genet 13: 705-719.

79. Collas P (2010) The current state of chromatin immunoprecipitation Molecular Biotechnology. 45: 87-100.

80. Bishop JB, Witt KL, Sloane RA (1997) Genetic toxicities of human teratogens. Mutat Res 396: 9-43.

81. Gurvich N, Berman MG, Wittner BS, Gentleman RC, Klein PS, et al. (2005) Association of valproate-induced teratogenesis with histone deacetylase inhibition in vivo. FASEB J 19: 1166-1168.

82. Fernandez AF, Assenov Y, Martin-Subero JI, Balint B, Siebert R, et al. (2012) A DNA methylation fingerprint of 1628 human samples. Genome Res 22: 407-419.

83. Chiang AC, Massagué J (2008) Molecular basis of metastasis. N Engl J Med 359: 2814-2823.

84. Chuang JC, Jones PA (2007) Epigenetics and microRNAs. Pediatr Res 61: 24R-29R.

85. Clark SJ (2007) Action at a distance: epigenetic silencing of large chromosomal regions in carcinogenesis. Hum Mol Genet 16 Spec No 1: R88-R95.

86. Clouaire T, Stancheva I (2008) Methyl-CpG binding proteins: specialized transcriptional repressors or structural components of chromatin? Cell Mol Life Sci 65: 1509-1522.

87. Deplus R, Brenner C, Burgers WA, Putmans P, Kouzarides T, et al. (2002) Dnmt3L is a transcriptional repressor that recruits histone deacetylase. Nucleic Acids Res 30: 3831-3838.

88. Ducasse M, Brown MA (2006) Epigenetic aberrations and cancer. Mol Cancer 5: 60 .

89. Esteller M (2008) Epigenetics in cancer. N Engl J Med 358: 1148-1159.

90. Feinberg AP, Ohlsson R, Henikoff S (2006) The epigenetic progenitor origin of human cancer. Nat Rev Genet 7: 21-33.

91. Gargiulo G, Minucci S (2009) Epigenomic profiling of cancer cells. Int J Biochem Cell Biol 41: 127-135.

92. Paranjape T, Slack FJ, Weidhaas JB (2009) MicroRNAs: tools for cancer diagnostics. Gut 58: 1546-1554.
93. Dehan P, Kustermans G, Guenin S, Horion J, Boniver J, et al. (2009) DNA methylation and cancer diagnosis: new methods and applications. Expert Rev Mol Diagn 9: 651-657.

94. Brock MV, Hooker CM, Ota-Machida E, Han Y, Guo M, et al. (2008) DNA methylation markers and early recurrence in stage I lung cancer. N Engl J Med 358: 1118-1128.

95. Wilson AS, Power BE, Molloy PL (2007) DNA hypomethylation and human diseases. Biochim Biophys Acta 1775: 138-162.

96. Kondo Y (2009) Epigenetic cross-talk between DNA methylation and histone modifications in human cancers. Yonsei Med J 50: 455-463.

97. Barradas M, Anderton E, Acosta JC, Li S, Banito A, et al. (2009) Histone demethylase JMJD3 contributes to epigenetic control of INK4a/ARF by oncogenic RAS. Genes Dev 23: 1177-1182.

98. Seligson DB, Horvath S, McBrian MA, Mah V, Yu H, et al. (2009) Global levels of histone modifications predict prognosis in different cancers. Am J Pathol 174: 1619-1628.

99. Esteller M, Garcia-Foncillas J, Andion E, Goodman SN, Hidalgo OF, et al. (2000) Inactivation of the DNA-repair gene MGMT and the clinical response of gliomas to alkylating agents. N Engl J Med 343: 1350-1354.

100. Hegi ME, Diserens AC, Gorlia T, Hamou MF, de Tribolet N, et al. (2005) MGMT gene silencing and benefit from temozolomide in glioblastoma. $\mathrm{N}$ Engl J Med 352: 997-1003.

101. Esteller M, Gaidano G, Goodman SN, Zagonel V, Capello D, et al. (2002) Hypermethylation of the DNA repair gene $\mathrm{O}(6)$-methylguanine DNA methyltransferase and survival of patients with diffuse large B-cell lymphoma. J Natl Cancer Inst 94: 26-32.

102. Nand S, Achille N, Othus M, Phelan KW, Zhang S, et al. (2015) Association between early promoter methylation changes and outcome in older acute myeloid leukemia patients treated on SWOG S0703 (NCT0065884). ASCO Annual Meeting Proceedings 33: 7060.

103. Schulz WA, Hoffmann MJ (2009) Epigenetic mechanisms in the biology of prostate cancer. Semin Cancer Biol 19: 172-180.

104. Domschke K, Tidow N, Schwarte K, Ziegler C, Lesch KP, et al. (2015) Pharmacoepigenetics of depression: no major influence of MAO-A DNA methylation on treatment response. J Neural Transm (Vienna) 122: 99-108.

105. Božić T, Lin Q, Frobel J, Wilop S, Hoffmann M, et al. (2015) DNAmethylation in $\mathrm{C} 1 \mathrm{R}$ is a prognostic biomarker for acute myeloid leukemia. Clin Epigenetics 7: 116.

106. Weidner CI, Lin Q, Birkhofer C, Gerstenmaier U, Kaifie A, et al. (2016) DNA methylation in PRDM8 is indicative for dyskeratosis congenita. Oncotarget 7: 10765-10772.

107. Jost E, Lin Q, Weidner CI, Wilop S, Hoffmann M, et al. (2014) Epimutations mimic genomic mutations of DNMT3A in acute myeloid leukemia. Leukemia 28: 1227-1234.

108. Ponchel F, Burska A, Raschke E, Olek S, Emery P (2016) A8.11 Th17 cells as a diagnostic biomarker for rheumatoid arthritis (RA): Pilot data using an epigenetic QPCR assay. Ann Rheum Dis 75: A69.

109. Jung Y, Park J, Kim T, Park JH, Jong HS, et al. (2007) Potential advantages of DNA methyltransferase 1 (DNMT1)-targeted inhibition for cancer therapy. J Mol Med (Berl) 85: 1137-1148.

110. Lyko F, Brown R (2005) DNA methyltransferase inhibitors and the development of epigenetic cancer therapies. J Natl Cancer Inst 97: 1498-1506.

111. Bots M, Johnstone RW (2009) Rational combinations using HDAC inhibitors. Clin Cancer Res 15: 3970-3977.

112. Cang S, Ma Y, Liu D (2009) New clinical developments in histone deacetylase inhibitors for epigenetic therapy of cancer. J Hematol Oncol 2: 22 .

113. Bruserud Ø, Stapnes C, Ersvaer E, Gjertsen BT, Ryningen A (2007) Histone deacetylase inhibitors in cancer treatment: a review of the clinical toxicity and the modulation of gene expression in cancer cell. Curr Pharm Biotechnol 8: 388-400.

114. Zhou Y1, Lu Q (2008) DNA methylation in T cells from idiopathic lupus and drug-induced lupus patients. Autoimmun Rev 7: 376-383. 
115. Lee BH, Yegnasubramanian S, Lin X, Nelson WG (2005) Procainamide is a specific inhibitor of DNA methyltransferase 1. J Biol Chem 280: 40749-40756

116. Deng C, Lu Q, Zhang Z, Rao T, Attwood J, et al. (2003) Hydralazine may induce autoimmunity by inhibiting extracellular signal-regulated kinase pathway signaling. Arthritis Rheum 48: 746-756.

117. Gorelik G, Fang JY, Wu A, Sawalha AH, Richardson B (2007) Impaired T cell protein kinase $\mathrm{C}$ delta activation decreases ERK pathway signaling in idiopathic and hydralazine-induced lupus. J Immunol 179: 5553-5563.

118. Quddus J, Johnson K, Gavalchin J, Amento E, Chrisp C, et al. (1993) Treating activated CD4+ $\mathrm{T}$ cells with either of two distinct DNA methyltransferase inhibitors, 5-azacytidine or procainamide, is sufficient to cause a lupus-like disease in syngeneic mice. J Clin Invest 92: 38.

119. Yung RL, Quddus J, Chrisp CE, Johnson KJ, Richardson BC (1995) Mechanisms of drug-induced lupus: I. Cloned Th2 cells modified with DNA methylation inhibitors in vitro cause autoimmunity in vivo. J Immunol 154: 3025-3035.

120. Cornacchia E, Golbus J, Maybaum J, Strahler J, Hanash S, et al. (1988) Hydralazine and procainamide inhibit $\mathrm{T}$ cell DNA methylation and induce autoreactivity. J Immunol 140: 2197-2200.

121. McKay JA, Mathers JC (2011) Diet induced epigenetic changes and their implications for health. Acta Physiol (Oxf) 202: 103-118.

122. Waterland RA (2006) Assessing the effects of high methionine intake on DNA methylation. J Nutr 136: 1706-1710.
123. Johnson IT, Belshaw NJ (2008) Environment, diet and CpG island methylation: epigenetic signals in gastrointestinal neoplasia. Food Chem Toxicol 46: 1346-1359.

124. Schalinske KL (2003) Interrelationship between diabetes and homocysteine metabolism: hormonal regulation of cystathionine [beta]synthase. Nutr Rev 61: 136.

125. McCarty MF (2000) Insulin secretion as a potential determinant of homocysteine levels. Med Hypotheses 55: 454-455.

126. Wijekoon EP, Brosnan ME, Brosnan JT (2007) Homocysteine metabolism in diabetes. Biochem Soc Trans 35: 1175-1179.

127. Myzak MC, Dashwood RH (2006) Histone deacetylases as targets for dietary cancer preventive agents: lessons learned with butyrate, diallyl disulfide, and sulforaphane. Curr Drug Targets 7: 443-52.

128. Guarente L, Picard F (2005) Calorie restriction--the SIR2 connection. Cell 120: 473-482.

129. Pandey M, Shukla S, Gupta S (2010) Promoter demethylation and chromatin remodeling by green tea polyphenols leads to re-expression of GSTP1 in human prostate cancer cells. Int J Cancer 126: 2520-2533.

130. Wang LG, Beklemisheva A, Liu XM, Ferrari AC, Feng J, et al. (2007) Dual action on promoter demethylation and chromatin by an isothiocyanate restored GSTP1 silenced in prostate cancer. Mol Carcinog 46: 24-31.

131. Herceg $Z$ (2007) Epigenetics and cancer: towards an evaluation of the impact of environmental and dietary factors. Mutagenesis 22: 91-103. 